\title{
Conexões
}

\section{As propostas de educação física nas Conferências Populares da Glória no ano de 1878}

Felipe Lameu dos Santos ${ }^{1}$

\section{RESUMO}

Este trabalho tem o objetivo de socializar algumas impressões iniciais sobre as propostas de educação física contidas nas Conferências Populares da Glória nos anos finais do século XIX. Os documentos tornados fontes foram duas conferências proferidas sobre educação física no ano 1878, a conferência inaugural proferida no dia 23 de novembro de 1873 e o Relatório do Ministério do Império referente ao ano de 1873. Nas conferências, percebe-se que a educação física tinha um papel ligado à saúde e às medidas higiênicas. A higiene era o braço da medicina para interferir em vários espaços da vida das pessoas e a educação física um instrumento de intervenção da higiene.

Palavras Chave: Higiene. Conferências. Educação física.

\footnotetext{
${ }^{1}$ Universidade Federal Rural do Rio de Janeiro

Submetido em: 20 maio 2017

Aceito em: 25 set. 2017

Contato: felipelameu@gmail.com
} 


\section{The proposals of physical education in the Conferências Populares da Glória in the year of 1878}

\section{ABStract}

This work has the objective to socialize some initial views on the proposals contained in physical education lectures given in the Conferências Populares da Glória in the final years of the nineteenth century. Sources documents were two lectures given on physical education on 1878, the inaugural lecture on 23 November 1873 and the Ministry of the Report of the 1873 Empire and the Report. In the conference, it is clear that physical education had a very linked to health and hygiene measures paper. Hygiene was the medical arm to interfere in various areas of people's lives and physical education a hygiene intervention instrument.

Keywords: Hygiene. Conferences. Physical education.

\section{Las propuestas de educación física em las Conferências Populares da Glória en el año de 1878}

\section{RESUMEN}

Este trabajo tiene el objetivo de socializar algunas impresiones iniciales sobre las propuestas de educación física contenidas en las Conferências Populares da Glória en los años finales del siglo XIX. Los documentos convertidos en fuentes fueron dos conferencias pronunciadas sobre educación física en el año 1878, la conferencia inaugural dictada el 23 de noviembre de 1873 y el Informe del Ministerio del Imperio de. En las conferencias, se percibe que la educación física tenía un papel vinculado a la salud ya las medidas higiénicas. La higiene era el brazo de la medicina para interferir en varios espacios de la vida de las personas y la educación física un instrumento de intervención de la higiene.

Palabras Clave: Higiene. Conferencias. Educación física. 


\section{INTRODUÇÃO}

Na busca de colocar o Brasil no caminho traçado pelos países "civilizados", a educação da população baseada nos conhecimentos científicos tornou-se um dos pilares fundamentais do Brasil nos anos finais do século XIX (SCHUELER, 1997). A ciência era vista pelas camadas letradas da população como veículo responsável pela civilização. Difundir o saber científico era necessário e as conferências públicas foram disseminadas no século XIX com esse intuito (BASTOS, 2003). Dentre elas, as Conferências Populares da Glória, criadas pelo Conselheiro Manoel Francisco Correia ${ }^{1}$, foram das mais importantes no Brasil nos anos finais do século XIX.

As Conferências Populares da Glória começaram no ano de 1873 e se estenderam até as primeiras décadas do século XX (CARULA, 2009). Nelas eram discutidos temas científicos, econômicos, políticos, culturais, educacionais e higiênicos, sendo o período de maior número de conferências as décadas de 1870 e 1880: entre 1873 e 1889 ocorreram 596 preleções, proferidas por 145 oradores (CARULA, 2012).

Em teses defendidas na Faculdade de Medicina do Rio de Janeiro pode-se encontrar a defesa de que a educação física deveria ser ensinada nas conferências públicas com o intuito de higienizar a população da cidade do Rio de Janeiro (LAMEU, 2016). Entretanto poucos trabalhos no campo de História da Educação Física realizaram o esforço de compreender as possíveis formas de educação física defendidas em conferências públicas no Brasil do final do século XIX. Este artigo é um primeiro esforço em compreender as defesas da educação física no espaço educativo não escolar das Conferências Populares da Glória.

O termo educação física utilizado no Brasil do século XIX diferencia-se bastante do entendimento da Educação Física como área de estudos e disciplina escolar intimamente relacionada ao corpo em movimento como hodiernamente entende-se. Nesse artigo, optou-se pela utilização, no trato das fontes, do termo educação física tal qual designava a documentação pesquisada, buscou-se entender a educação física como uma expressão de época dentro de seu contexto social e cultural.

\footnotetext{
${ }^{1}$ Correia nasceu em Paranaguá no dia $1^{\circ}$ de novembro de 1831 Estudou no Educandário Nova Friburgo e formou-se bacharel em letras pelo Imperial Colégio de Pedro II. Posteriormente, formou-se bacharel em direito pela Faculdade de Direito de São Paulo. Em 1862 foi nomeado presidente da província de Pernambuco, tendo exercido o cargo de 30 de abril a 2 de outubro daquele ano. De 1869 a 1877 foi deputado geral pela província do Paraná e de 1874 a 1875 exerceu a presidência da Câmara dos Deputados. Concomitantemente ao mandato de deputado geral, assumiu também o Ministério dos Estrangeiros de 1871 a 1873, no gabinete chefiado por José Maria da Silva Paranhos, então visconde do Rio Branco. Como ministro, exerceu papel de destaque nas negociações de paz após o término da Guerra do Paraguai. Em 1874, foi o responsável pela criação da primeira Escola Normal do Rio de Janeiro. Dedicou-se à causa da instrução pública, tendo fundado diversas escolas, museus e bibliotecas. Em 1877 assumiu o cargo de conselheiro de Estado. De 1877 a 1889 foi senador pela província do Paraná. Nesse período, em 25 de fevereiro de 1883, fundou, junto com outros senadores, a Sociedade de Geografia do Rio de Janeiro. Ainda durante o Império foi segundo oficial da Secretaria da Fazenda e primeiro oficial da Secretaria do Império e depois da Secretaria de Justiça, além de oficial de gabinete de ministros de Estado. Também foi diretor da Repartição de Estatística, tendo sido responsável pela realização do primeiro recenseamento da população no Império.

Conexões: Educ. Fís., Esporte e Saúde, Campinas: SP, v. 15, n 4, p. 410-418, out./dez. 2017. ISSN: 1980-9030
} 


\section{As Conferências Populares da GLÓRIA: ESPAÇO DE INSTRUÇÃO CIENTÍFICA}

A primeira preleção das Conferências Populares da Glória teve como tema o ensino obrigatório, sendo proferida pelo seu fundador Conselheiro Manoel Francisco Correia, o qual dizia que o objetivo principal das Conferências era instruir o "povo" com o conhecimento científico (CORREIA, 1876). As conferências eram pensadas como um espaço educativo e de divulgação do saber científico para leigos para que adotassem esses saberes em suas vidas e atuassem num projeto de construção da nação brasileira.

Contudo, as portas da tribuna da Glória não estavam abertas ao "povo". Para assistir as Conferências Populares da Glória era necessário possuir um cartão de entrada que era distribuído previamente pelo Conselheiro Manoel Francisco Corrêa e pelo orador (CARULA, 2012), o que fazia com que a plateia fosse constituída por um público seleto, contando, por vezes, com a presença do Imperador e de sua família, da aristocracia da Corte, profissionais liberais e estudantes (FONSECA, 1996). Excluía-se a população mais pobre que, na visão das elites do período, era a que mais necessitava ser "civilizada" no processo de construção do Brasil.

Seu caráter pouco popular, apesar do nome de Conferências Populares, era uma das principais críticas direcionadas às Conferências. Contudo, para o Conselheiro Manoel Francisco Correia, essa crítica não era um problema, pois ele entendia que o "popular" nas conferências era o fato de divulgar o conhecimento entre as camadas letradas para que essas levassem aos iletrados do Brasil os conhecimentos científicos (CARULA, 2009). O papel das Conferências, nesse sentido, era dar instrumentos baseados nos conhecimentos científicos para as elites letradas civilizarem as camadas pobres, era criar uma elite civilizadora.

As conferências aconteciam às onze horas aos domingos e às dezoito às quintasfeiras. Desde seu inicio, elas eram noticiadas em jornais de grande circulação. Por vezes, os resumos das conferências eram publicados bem como debates sobre os temas propostos, fazendo com que as discussões e os temas reverberassem para além da plateia da Escola da Glória (CARULA, 2009).

O sucesso das Conferências era tão grande que chegou a ser publicado um periódico especialmente voltado para registrar seus conteúdos na íntegra. Esse periódico, chamado de Conferências Populares, foi publicado entre os anos de 1876 e 1877, perfazendo 10 números. Nele, foram publicados, integralmente os textos das conferências realizadas em seu período de circulação e o conteúdo das preleções 
anteriores à publicação do primeiro número. Os exemplares podiam ser adquiridos de modo avulso ou por meio de assinatura dentro e fora da Corte (CARULA, 2009).

A iniciativa do Conselheiro Manoel Francisco Correia contava com o apoio do governo. O governo apoiou o projeto cedendo o espaço para a realização das conferências. Pode-se ler no relatório do Ministério do Império, referente ao ano de 1873, felicitações relativas à iniciativa do Conselheiro Correia. Segundo o relatório, as conferências atuariam na "elucidação de assuntos relativos ao desenvolvimento da instrução e interesse moral do povo” (BRASIL, 1874, p. 8).

Dentre os temas relativos à instrução, formação moral e higiênica do povo podiase encontrar a educação física. A educação física foi tratada em duas conferências por seu próprio fundador, Conselheiro Manoel Francisco Correia. Ambas as conferências foram realizadas no ano de 1878. Essas conferências foram publicadas posteriormente, no ano de 1885, em obra posterior que compilou as conferências proferidas por Manoel Correia em diversos espaços (CORREIA, 1885).

\section{As Conferências sobre EducaÇão FÍSICA: A EDUCAÇÃO INTEGRAL HIGIÊNICA}

No Brasil do século XIX a educação física poderia abarcar uma série ampla de práticas e não apenas os exercícios físicos. No Rio de Janeiro dos nos anos finais do século XIX a educação física abarcava uma ampla gama de aspectos como: a ginástica, a arquitetura dos edifícios, a alimentação, as formas de excreção, o banho, o asseio, a dança, o canto e a declamação, a natação, a esgrima, os jogos, o Sport, a equitação, os passeios e a caça. Tudo que dizia respeito ao desenvolvimento físico podia ser enquadrado de alguma forma na educação física (MELO; PERES, 2014; LAMEU, 2016). Nas conferências proferidas por Correia na tribuna da glória, a ginástica era o principal elemento da educação física. Contudo, isso não significava dizer que ele desconsiderava a amplitude do tema. Segundo ele, a educação física abarcava a vestimenta, a alimentação e o asseio, mas a ênfase dada seria sobre à ginástica (CORREIA, 1885a).

Segundo Correia (1885b, p. 259), "não é uma alma, não é um corpo que se educa, mas um homem." Foi com essa citação de Montaigne, que segundo Bastos (2003) era um autor que destacava o papel formativo e educativo das conferências públicas no século XVI, que o Conselheiro Correia começou uma de suas conferências sobre o tema da educação física. O modelo de educação defendido por ele deveria abarcar dimensões intelectuais, morais e físicas, visando formar as pessoas em sua inteireza. Seu modelo Conexões: Educ. Fís., Esporte e Saúde, Campinas: SP, v. 15, n 4, p. 410-418, out./dez. 2017. ISSN: 1980-9030 
de educação tinha como objetivo regenerar a população brasileira. Para isso, seria necessário ocorrer um equilíbrio entre as dimensões físicas, morais e intelectuais na educação. Porém, segundo ele, não era o que acontecia no Brasil, principalmente, quando o tema relacionava-se à educação física (CORRERIA, 1885a).

O Conselheiro Correia apontou na conferência de 1 de setembro de 1878, que a educação física estava sendo deixada de lado por causa do componente religioso ligado à educação desde o século XVII. A partir dessa afirmação, o conselheiro sugeria que "ao nosso século [século XIX] coube, entre outras obras meritórias, a restauração da ginástica, com o devido apreço à educação física.” (CORREIA, 1885a, p. 254).

Como Correia defendia um equilíbrio entre as dimensões da educação, para ele, a educação física não prejudicaria o intelecto, pelo contrário, ela fortificava o corpo, possibilitando maior capacidade intelectual. Em sua visão, defender a educação física não era um "culto à matéria", mas sim uma busca do equilíbrio entre as educações para formar os brasileiros de forma integral, os tornando fortes e saudáveis.

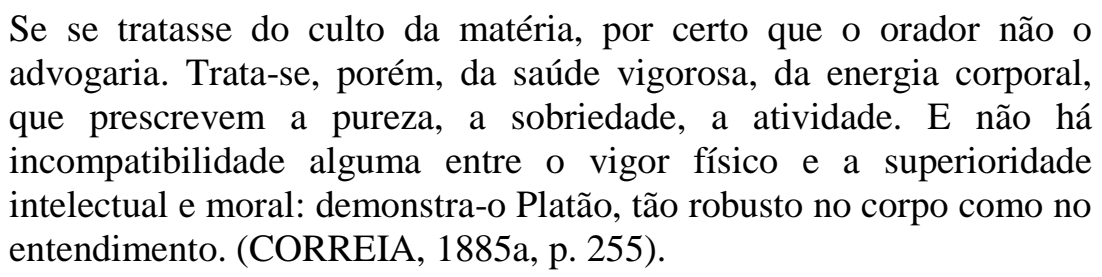

Segundo Manoel Correia, nesse modelo de formação integral, educação deveria ser estendida para ambos os sexos sem ser a mesma para ambos. A educação física da mulher e do homem deveriam ser diferentes, pois cada um dos sexos deveria ocupar um lugar na sociedade determinado pela "natureza". Segundo Correia, à mulher caberia o papel de ser mãe, ao homem o de ser pai e cidadão. Apenas a ginástica natural deveria ser utilizada para os dois sexos, já os "exercícios especiais" deveriam se ligar aos papéis futuros que ambos deveriam ocupar na sociedade (CORREIA, 1885b).

Correia argumentava em seu texto que "raças inferiores" contribuíram para a formação do Brasil e que uma raça que convinha à grandeza das riquezas naturais que o Brasil possuía deveria ser formada pela educação em todas as suas dimensões (CORREIA, 1885b). Com esse entendimento, para ele, apesar da constituição racial brasileira, o país poderia ser regenerado pela educação física e intelectual, dando à educação integral papel fundamental na construção da raça e da nação. Para isso acontecer, ele defendia que a educação deveria ser aplicada desde infância, em todos os seus aspectos, na família, na escola e no colégio, e para ambos os sexos, para que o Brasil pudesse possuir uma raça forte e vigorosa (CORREIA, 1885a).

Todavia, não era isso que ele observava no Brasil. Ele dizia que bastava olhar para as escolas para ver meninos "raquíticos, pálidos e nervosos" porque nas escolas não se adotava nenhum tipo de exercício físico: "não se atende se quer (sic) aos 
exercícios da ginástica natural, os longos passeios ao ar livre, o movimento, a carreira, o salto, a natação, a esgrima, a equitação, os jogos que desenvolvem a agilidade, a destreza, a força." (CORREIA, 1885a, p. 256). Correia defendia que uma cultura escolar higiênica pela educação física deveria superar a escola e a educação vigentes naquele momento.

\section{Considerações Finais}

Nas conferências sobre educação física, proferidas por Manuel Correia nas Conferências Públicas da Glória, percebe-se que a educação física tinha um papel muito ligado à saúde e às medidas higiênicas. Em sua visão, a higiene era o braço da medicina para interferir em vários espaços da vida das pessoas e a educação física um instrumento de intervenção da higiene. Embora o saber médico não fosse o único possível de intervenção sobre o corpo no contexto do Rio de Janeiro do final do século XIX (CHALHOUB, 1996; BENCHIMOL, 1992; SAMPAIO, 1995), nos argumentos do Conselheiro Correia, em defesa da educação física e de sua escolarização a partir de uma cultura escolar higiênica, podia-se perceber uma forte conotação do saber médico oficial.

As conferências públicas tiveram grande repercussão nos contexto do Rio de Janeiro e do Brasil do final do século XIX, contudo poucas pesquisas foram realizadas no sentido de compreender as formas de educação física defendidas nesses espaços, sua circulação, seus agentes e sua possível repercussão no cotidiano escolar da época. Esse artigo foi um dos primeiros esforços nesse sentido. Outras conferências, como as Conferências Pedagógicas, ainda aguardam as perguntas dos historiadores da Educação Física para se tornarem fontes do conhecimento histórico.

\section{REFERÊnCIAS Documentais}

BRASIL. Directoria Geral de Estatística. Relatório e Trabalhos Estatisticos apresentados ao Ilmo. E Exmo. Snr Conselheiro Dr. José Bento da Cunha e Figueiredo, Ministro e Secretario de Estado dos Negocios do Império pelo Director Conselheiro Manoel Francisco Correia em 31 de dezembro de 1876. Rio de Janeiro, 1877.

BRASIL. Ministério do Império. Ministro (João Alfredo Corrêa de Oliveira). Relatório do anno de 1873 apresentado a Assembléia Geral na 3ª Sessão da 15ª Legislatura, 1874.

CORREIA, Manoel Francisco. Educação Physica: conferencia em 1 de setembro de 1878. Conferencias e outros trabalhos do Conselheiro Manoel Francisco Correia. Rio de Janeiro: Typographia Perseverança, 1885a. 
CORREIA, Manoel Francisco. Educação Physica: conferencia em 20 de novembro de 1878. Conferencias e outros trabalhos do Conselheiro Manoel Francisco Correia. Rio de Janeiro: Typographia Perseverança, 1885b.

Ensino obrigatório: inauguração das conferencias no edifício das escolas publicas da freguezia da Gloria. $1^{\text {a }}$ Conferência de 23 de novembro de 1873. Conferencias Populares, n. 4, abr. 1876.

\section{REFERÊNCIAS}

BASTOS, Maria Helena Câmara. As conferências pedagógicas dos professores primário do município da Corte: permuta das luzes e idéias (1873 - 1886). In: SIMPÓSIO NACIONAL DE HISTÓRIA, 22., 2003, João Pessoa. Anais... João Pessoa: ANPUH, 2003.

BENCHIMOL, Jaime Larry. Pereira Passos um Haussmann tropical: a renovação urbana da cidade do Rio de Janeiro no início do século XX. Rio de Janeiro: Secretária Municipal de Cultura, Turismo e Esporte, Departamento Geral de Documentação e informação Cultural, Divisão de Editoração, 1992.

CARULA, Karoline. Darwinismo, raça e gênero: conferências e cursos públicos no Rio de Janeiro (1870-1889). 2012. 302 f. Tese (Doutorado em História) Universidade Federal Fluminense, Niterói, 2012.

A tribuna da ciência: as conferências populares da Glória e as discussões do Darwinismo na imprensa carioca (1873-1880). São Paulo: Annablume: Fapesp, 2009.

CARVALHO, José Murilo de. A vida política. In: CARVALHO, José Murilo de. A construção nacional: 1830-1889. Rio de Janeiro: Objetiva, 2012. v. 2.

CHALHOUB, Sidney. Cidade febril: cortiços e epidemias na corte imperial. São Paulo: Companhia das Letras, 1996.

População e Sociedade. In: CARVALHO, J. M. A construção nacional: 18301889. Rio de Janeiro: Objetiva, 2012. v. 2.

FONSECA, Maria Rachel Fróes da. As Conferências Populares da Glória: a divulgação do saber científico. História, Ciências, Saúde-Manguinhos, Rio de Janeiro, v. 2, n. 3, p. 135-166, 1996. 
LAMEU, Felipe. Formas de higienizar por meio de educação física segundo teses, conferências e periódicos médicos do Rio de Janeiro entre 1870 e 1892. 2016, 142f. Dissertação (Mestrado em Educação) - Universidade Federal Fluminense, Niterói, 2016.

MELO, Victor Andrade de; PERES, Fabio Faria. O corpo da nação: posicionamentos governamentais sobre a educação física no Brasil monárquico. História, Ciências, Saúde - Manguinhos, v. 21, p. 1131-1150, 2014.

SAMPAIO, Gabriela dos Reis. Nas trincheiras da cura: as diferentes medicinas no Rio de Janeiro Imperial. 1995. 199 f. Dissertação (Mestrado em História) - Universidade Estadual de Campinas, Campinas, 1995.

SCHUELER, Alessandra Frota Martinez. Educar e instruir: a instrução popular na Corte Imperial-1870 a 1889. 1997. 300f. Dissertação (Mestrado em História) Universidade Federal Fluminense, Niterói, 1997. 